\title{
The man that lost (part of) his mind
}

\author{
Finlay Brown, ${ }^{1}$ Djamil Vahidassr ${ }^{2}$
}

${ }^{1}$ General Practice, Northern Ireland Medical and Dental Training Agency, Belfast, UK ${ }^{2}$ Care of The Elderly and Stroke, Antrim Area Hospital, Antrim, Co Antrim, UK

Correspondence to Dr Finlay Brown, finlaybrown@googlemail.com

Accepted 6 February 2018
Check for updates

To cite: Brown F, Vahidassr D. BMJ Case Rep Published Online First: [please include Day Month Year]. doi:10.1136/bcr-2017222892

\section{SUMMARY}

An 84-year-old man presented to the emergency department following recurrent falls over several weeks and onset of new left-sided weakness. CT of the brain revealed a large air cavity (pneumatocoele) in the right frontal lobe thought to be secondary to an ethmoidal osteoma communicating through the cribriform plate allowing air to be forced into the skull under pressure. Subsequent MRI confirmed these findings and also revealed a small focal area of acute infarction in the adjacent corpus callosum. The patient had a prolonged hospital stay, declined neurosurgical intervention and was discharged home on secondary stroke prevention.

\section{BACKGROUND}

Falls and/or loss of balance are relatively common in the elderly. There is generally a lower threshold for imaging when these symptoms are associated with unilateral weakness. Stroke can be multifactorial in its aetiology. Pneumocephalus is not an uncommon complication of ENT (ear, nose and throat) and neurosurgical procedures. In this age group arteriosclerotic/embolic disease is the most common cause; however, rare causes must also be considered.

\section{CASE PRESENTATION}

An 84-year-old man was referred to the emergency department by his general practitioner having been complaining of recurrent falls and feeling unsteady over several months. He then developed a 3-day history of left-sided arm and leg weakness. There was no confusion, facial weakness, visual or speech disturbance, and he was feeling otherwise well. His medical history included glaucoma, meningitis (25 years ago) and nasal polypectomy many years ago. Regular medications were atorvastatin and HyloForte, timolol and bimatoprost eye-drops. He was otherwise fit and well, independent with physical activities of daily living (PADLs) and lived at home with his wife and two sons. He was a non-smoker and drank alcohol rarely.

Central nervous system (CNS) examination revealed normal range of eye movements, visual fields, speech and swallow. Peripheral nervous system (PNS) examination revealed $4 / 5$ power in the left upper and lower limbs with normal tone, power, sensation, coordination and reflexes including plantar response.

\section{INVESTIGATIONS}

Routine blood testing detected no abnormality.
CT of the brain showed a large $(9 \mathrm{~cm})$ air-filled cavity within the right frontal lobe with dystrophic calcification/osseous nodularity of the cribriform plate and paranasal sinuses. This was felt to be a pneumatocoele with some local mass effect and distortion of the frontal horn of the right lateral ventricle, effacement of surrounding sulci but no significant midline shift or oedema (figure 1).

MRI of the head helped confirm the presence of pneumatocoele within the right frontal lobe extending from the cribriform plate, as well as a large osteoma within the ethmoidal air cells with minimal mass effect, likely to be of a chronic nature (figure 2).

There was a small focal area of acute ischaemia with restricted diffusion to the right side of corpus callosum. Other than a small right vertebral artery, normal intracranial vascular flow voids were demonstrated (figure 3).

Ultrasound scan (USS) Doppler of the carotid arteries was normal.

\section{DIFFERENTIAL DIAGNOSES}

- pneumatocoele-the most likely diagnosis radiologically, specially given history of sinus disease

- neoplasm

- developmental/congenital lesion (no previous imaging available).

\section{TREATMENT}

The patient underwent a period of observation and rehabilitation. Following discussion with the neurosurgical team, he was offered surgery which would have involved a frontal craniotomy and suture repair of the dural defect after evacuation of the pressurised air cavity as well as excision of the osteoma performed by ENT. The patient made an informed decision not to proceed with surgery given risks and benefits.

\section{OUTCOME AND FOLLOW-UP}

The inpatient stay was prolonged by a lower respiratory tract infection. The patient was commenced on secondary stroke prevention and was advised to reattend in the event of worsening symptoms. The left-sided weakness was noted to have resolved on follow-up 12 weeks later and he remained well.

\section{DISCUSSION}

Pneumatocoeles within the brain (pneumocephalus) are seen in variable degrees of frequency in craniofacial injuries, infections (sinuses, otitis) and 


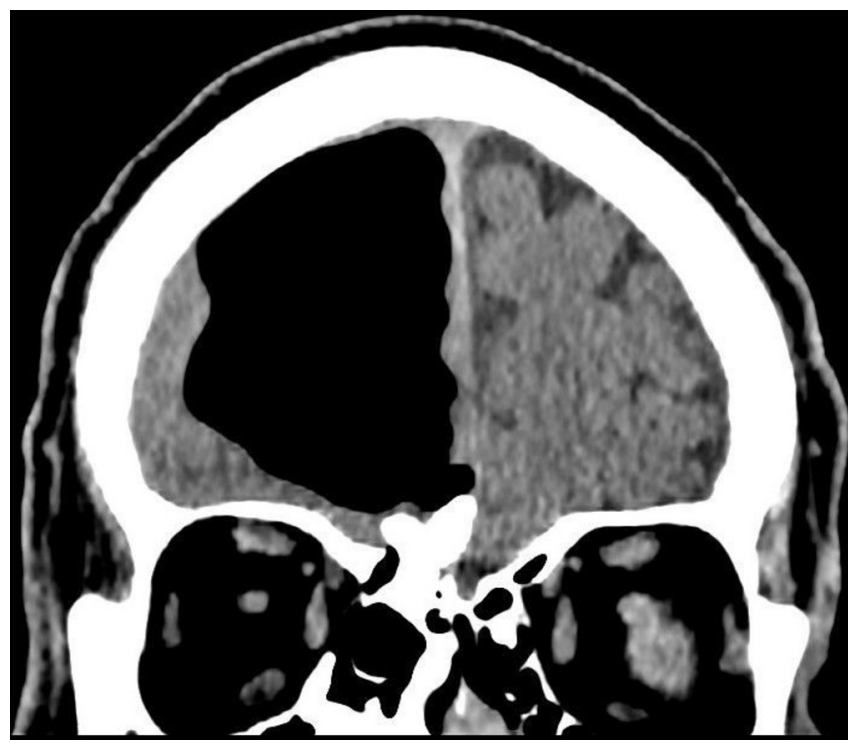

Figure 1 CT showing osteoma in paranasal sinus causing defect resulting in right pneumatocoele.

postsurgery for skull base tumours $(100 \%$ of craniotomy cases in one report). ${ }^{12}$

A small number of reported cases have been associated with history of ENT pathology, usually an osteoma, ${ }^{3}$ causing erosion through the cribriform plate and forcing air under pressure into the brain by creating a 'one-way valve' effect. This often causes the pneumatocoele to grow insidiously over weeks to months. Sometimes it can be precipitated by a more acute event, for example, following a bout of sneezing or coughing. It is a rarely reported complication of frontal sinus osteoma. ${ }^{45}$

Clinical presentation of a pneumocephalus can range from an asymptomatic incidental finding to presentation with headache, agitation, delirium, seizure, decreased mental status as well as focal neurological deficits depending on the

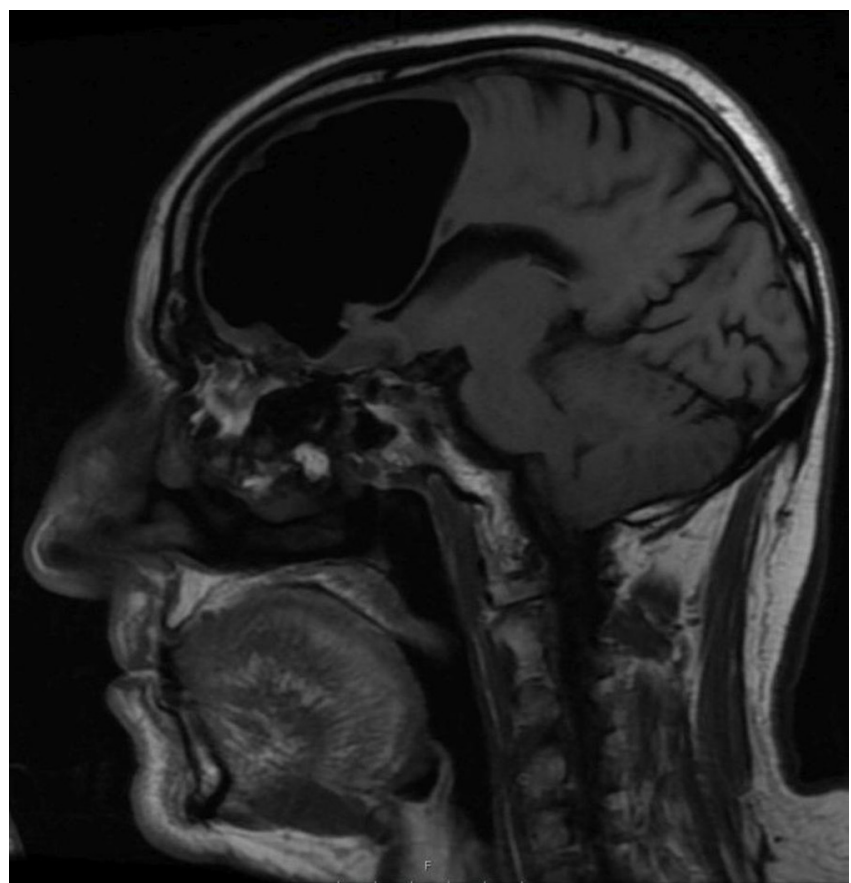

Figure 2 Sagittal view MRI showing right frontal air-filled cavity.

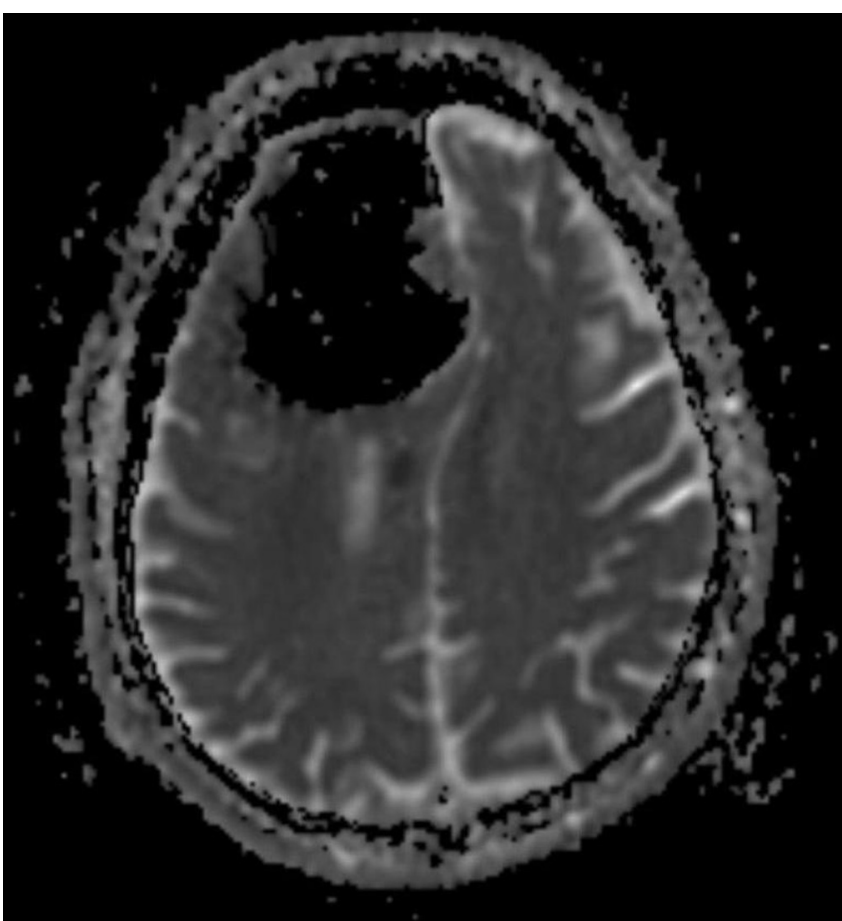

Figure 3 Diffusion-weighted MRI showing area of acute infarction.

location. ${ }^{6}$ These common, often non-specific symptoms are not infrequently encountered in primary care or accident and emergency (A\&E) consultation but would not commonly be attributed to a pneumocephalus unless aided by clinical suspicion and/or neuroimaging.

Although CT of the brain is usually the first imaging modality, diffusion-weighted MRI is the preferred imaging of choice to demonstrate cerebral ischaemia/infarction invisible on CT brain (CTB), as was the case with our patient. Pneumocephalus has been reported as a rare cause of stroke. ${ }^{7}$ CT or magnetic resonance angiogram would have been helpful to differentiate between tension pneumocephalus causing arterial obstruction with secondary ischaemia and arterial thrombosis.

Surgical management would require a dual approach, with the neurosurgical team evacuating the pressurised cavity and repairing the dural defect together and with ENT removing

\section{Learning points}

- A pneumatocoele is a pressurised air-filled cavity that when found in the brain can be termed a tension pneumocephalus.

- An erosion by an osteoma (common benign bone tumour) through the cribriform plate allowed air to gradually be pushed under pressure into the right frontal lobe causing resultant mass effect.

- Cerebral infarction may have been due to this pressure effect, and a CT angiogram would aid diagnosis.

- Management requires discussion with neurosurgical and ear, nose and throat teams to repair the defect as well as the cause, and understanding that conservative treatment is not without its risks.

- When assessing patients presenting to primary or secondary care with new onset of neurological symptoms, one should have a low threshold for imaging to help distinguish between common and rare causes. 
the offending osteoma to reduce the chance of recurrence. Conservative management with observation (as in our case) has been documented in some cases, with improvement in symptoms over time, but can also lead to worsening of symptoms or ascending infection (eg, ventriculitis). ${ }^{8}$ There were no plans for surveillance imaging in our patient as he completely refused surgery.

Contributors FB was personally involved with the care of the patient described in this case report. FB discussed the case at length with DV (stroke specialist), who helped with the construct of this case report, reviewing several drafts including relevant radiological figures.

Competing interests None declared.

Patient consent Obtained.

Provenance and peer review Not commissioned; externally peer reviewed.

(c) BMJ Publishing Group Ltd (unless otherwise stated in the text of the article) 2018. All rights reserved. No commercial use is permitted unless otherwise expressly granted.

\section{REFERENCES}

1 Eljamel MS, Foy PM. Post-traumatic CSF fistulae, the case for surgical repair. Br J Neurosurg 1990:4:479-83.

2 Satapathy GC, Dash HH. Tension pneumocephalus after neurosurgery in the supine position. Br J Anaesth 2000;84:115-7.

3 Rappaport JM, Attia EL. Pneumocephalus in frontal sinus osteoma: a case report. J Otolaryngol 1994;23:430-6.

4 Lehmer LM, Kissel P, Ragsdale BD. Frontal sinus osteoma with osteoblastoma-like histology and associated intracranial pneumatocele. Head Neck Pathol 2012;6:384-8.

5 Hackenbroch C, Kleinagel U, Hossfeld B. Tension pneumocephalus due to an osteoma of the frontal sinus. Dtsch Arztebl Int 2017;114:534.

6 Kankane VK, Jaiswal G, Gupta TK. Posttraumatic delayed tension pneumocephalus: Rare case with review of literature. Asian I Neurosurg 2016;11:343-7.

7 Bramley DC, Ghosh S. Tension pneumocephalus attributable to an ethmoid osteoma presenting as a stroke in evolution: an unusual presentation. Emerg Med J 2001;18:317-8.

8 Kwon J, Rha HK, Park HK, et al. Proper management of posttraumatic tension pneumocephalus. Korean J Neurotrauma 2017;13:158-61.

Copyright 2018 BMJ Publishing Group. All rights reserved. For permission to reuse any of this content visit http://group.bmj.com/group/rights-licensing/permissions.

BMJ Case Report Fellows may re-use this article for personal use and teaching without any further permission.

Become a Fellow of BMJ Case Reports today and you can:

- Submit as many cases as you like

Enjoy fast sympathetic peer review and rapid publication of accepted articles

- Access all the published articles

- Re-use any of the published material for personal use and teaching without further permission

For information on Institutional Fellowships contact consortiasales@bmjgroup.com

Visit casereports.bmj.com for more articles like this and to become a Fellow 